\title{
Mobile spinal enterogenous cyst resulting in intermittent paraplegia in a child: case report
}

\author{
Satoko Kojima, MD, 1 Junichi Yoshimura, MD, PhD, ${ }^{2}$ Tetsuro Takao, MD, PhD, ${ }^{2,3}$ \\ Tetsuro Tamura, MD, PhD, ${ }^{3}$ Kenichi Nishiyama, MD, PhD, ${ }^{2}$ Shigeru Maruyama, MD, ${ }^{1}$ \\ Masashi Suda, MD, ${ }^{1}$ and Yukihiko Fujii, MD, PhD²
}

\begin{abstract}
${ }^{1}$ Division of Pediatrics, Department of Medicine, Niigata Prefectural Central Hospital, Joetsu City; ${ }^{2}$ Department of Neurosurgery, Brain Research Institute, University of Niigata, Niigata City; and ${ }^{3}$ Department of Neurosurgery, Niigata Prefectural Central Hospital, Joetsu City, Niigata, Japan
\end{abstract}

\begin{abstract}
The authors report the case of a mobile spinal enterogenous cyst in a 2-year-old boy, who was admitted to the hospital several times for intermittent paraplegia. Magnetic resonance imaging and CT revealed an isolated cyst in the lumbar spinal canal. The symptoms were caused by transient myelopathy of the conus medullaris and radiculopathy of the cauda equina due to the changing size and location of the cyst. The cyst was surgically extirpated, after which the symptoms resolved. The histopathological diagnosis was enterogenous cyst. The clinical history of intraspinal enterogenous cyst is usually progressive. Mobility and changes in size are rare pathophysiological findings. The authors speculate that the cyst wall did not adhere to the surrounding structures and had ruptured and quickly reformed. Enterogenous cyst should be considered in the differential diagnosis of spinal intradural cysts in children with radiculomyelopathy.
\end{abstract}

http://thejns.org/doi/abs/10.3171/2016.4.PEDS15666

KEY WORDS neuroenteric cyst; enterogenous cyst; spinal intradural cyst; mobility; childhood; spine

$\Lambda$ $\mathrm{N}$ enterogenous cyst is an uncommon congenital abnormality that develops mainly in the spinal canal and accounts for about $0.4 \%$ of all spinal tumors. The cyst originates from an anomalous embryological connection between the primitive foregut and the developing neural tube. Vertebral abnormalities are often found in association with spinal enterogenous cysts presenting in childhood. ${ }^{12}$ They usually present as focal spinal cord compression syndromes whose symptoms vary according to the spinal level of the lesion. Pain is a common symptom and often radiates in nerve root distribution. ${ }^{10}$

The clinical history of enterogenous cysts is typically characterized by gradual progressive deterioration. These benign and potentially curable lesions should be surgically excised. ${ }^{4}$ They can present at any age but are most frequently diagnosed in the 4 th and 5 th decades of life. They have a male predominance $(60.4 \%)$ and present at a mean age of 6.4 years in the pediatric population. ${ }^{5}$

We describe a rare pediatric case of a mobile lumbar enterogenous cyst resulting in intermittent neurological symptoms.

\section{Case Report}

History

A boy 2 years, 2 months of age was admitted to our hospital because of an episode of paraplegia. He had a language delay but no medical history of trauma or meningitis. He had had 2 similar episodes of intermittent paraplegia. Hip arthritis and Perthes disease were considered. However, radiographic and CT images of the hip joints revealed no abnormalities. All episodes had begun just after coughing, after which he was unable to walk because of back pain. After those episodes, he was able to stand and walk again after a few days of rest.

\section{Examination}

A physical examination at this third episode revealed pyramidal tract signs, including increased deep tendon reflexes (Achilles and patellar tendon reflexes) and a positive Babinski sign. Magnetic resonance imaging of the lumbar spine revealed an intradural extramedullary cystic lesion on the ventral surface of the conus medullaris. The le- 
sion extended from L-1 to L-3 and compressed the conus medullaris. Both T1- and T2-weighted MRI showed that the lesion was isointense to the cerebrospinal fluid (CSF; Fig. 1). The preoperative diagnosis was arachnoid cyst, a symptomatic one whose appropriate treatment of choice was fenestration or extirpation. However, the patient's family desired a less invasive treatment, so we performed myelography and cyst puncture. The cyst moved from L1-L3 to T12-L1 during assessment, thus rendering cyst puncture unsuccessful (Fig. 2). As in the previous 2 episodes, the patient was able to stand and walk again in a few days.

Two months later, he was readmitted to our hospital because of a fourth episode of intermittent paraplegia. However, the physical examination findings differed from those in the previous episode. His bilateral lower-extremity reflexes were reduced, and radiculopathy was noted. Magnetic resonance images showed that the cyst had enlarged and migrated to L3-L4 (Fig. 3).

\section{Operation}

The patient was transferred to Niigata University Hos-

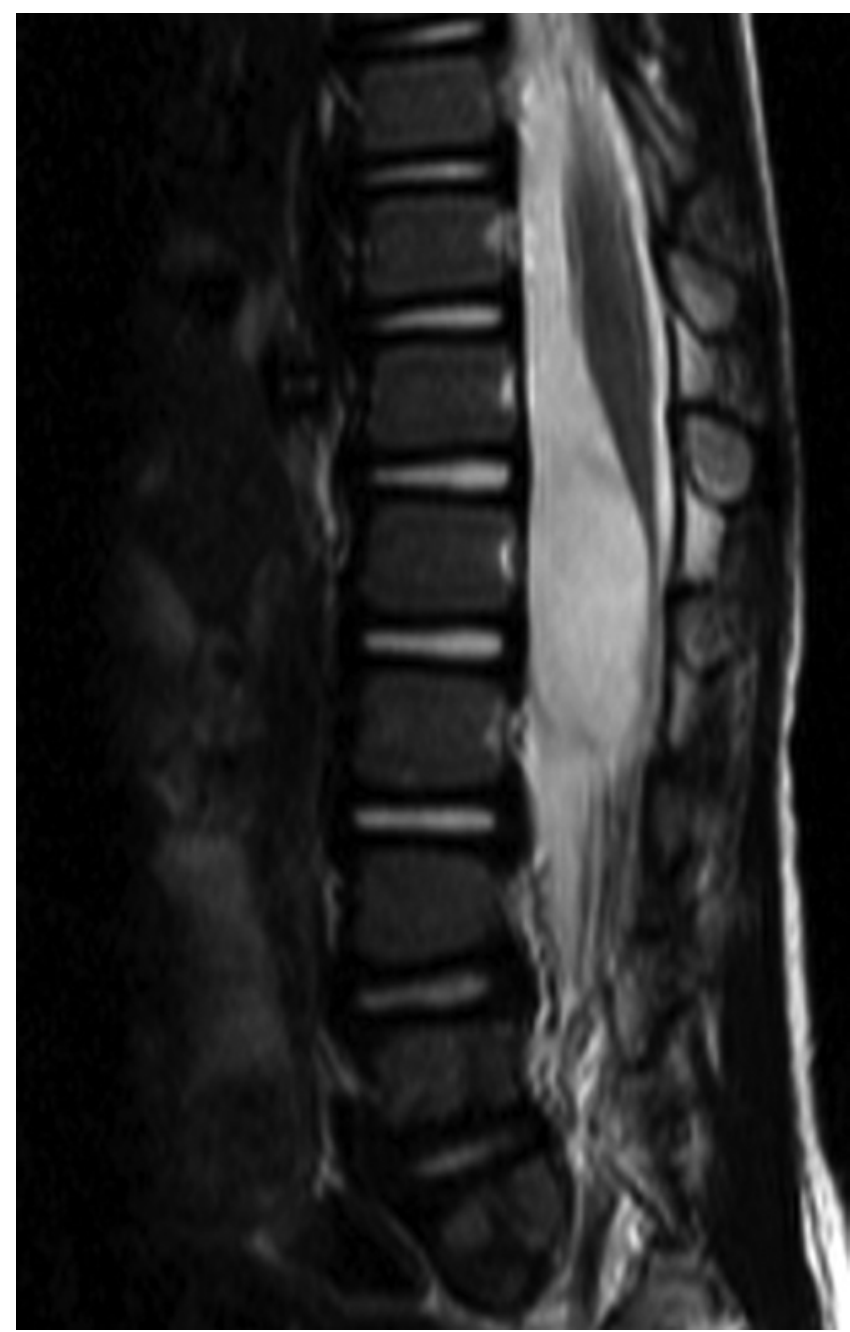

FIG. 1. Sagittal T2-weighted image, obtained at the third episode of gait disturbance, showing a lesion isointense to CSF. pital for surgery; however, preoperative MRI revealed remarkable shrinkage of the cyst (Fig. 4A). After a short monitoring period, the cyst again increased in size but remained in the lumbar region for over 4 months (Fig. 4B); thus, it was extirpated through laminotomy. During the surgery, the thin-walled translucent cyst was located in the subarachnoid space, ventral to the cauda equina. It did not adhere to surrounding structures and was removed en bloc without causing injury to the neurovascular tissues (Fig. $4 C)$.

\section{Pathological Findings}

Histological examination revealed that the cyst wall was composed of a columnar mucinous epithelium on delicate fibrous tissue, which confirmed the diagnosis of enterogenous cyst (Fig. 5).

\section{Postoperative Course}

The patient's postoperative course was uneventful, with no further episodes of paraplegia. He was discharged without neurological deficit. During the 35-month followup evaluation, he had no new symptoms and repeat MRI did not reveal any evidence of tumor recurrence or vertebral deformity.

\section{Discussion}

\section{General Features of Enterogenous Cysts}

Enterogenous cysts account for only $0.01 \%$ of central nervous system tumors. Intraspinal enterogenous cysts can occur at any level of the spinal cord but are most commonly found in the lower cervical and upper thoracic spine. ${ }^{9} \mathrm{~A}$ lumbosacral presentation is unusual; 8 only 36 cases have been reported in the English-language literature. ${ }^{3}$
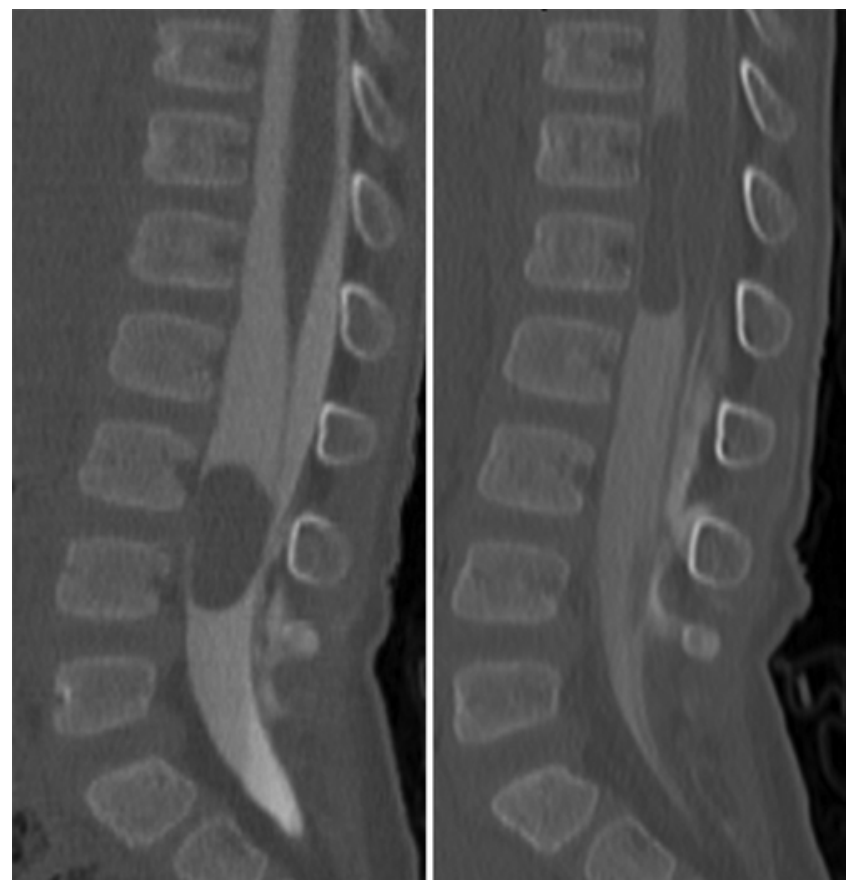

FIG. 2. Myelograms showing the mobile enterogenous cyst. The cyst moved from L1-L3 (left) to T12-L1 (right). 


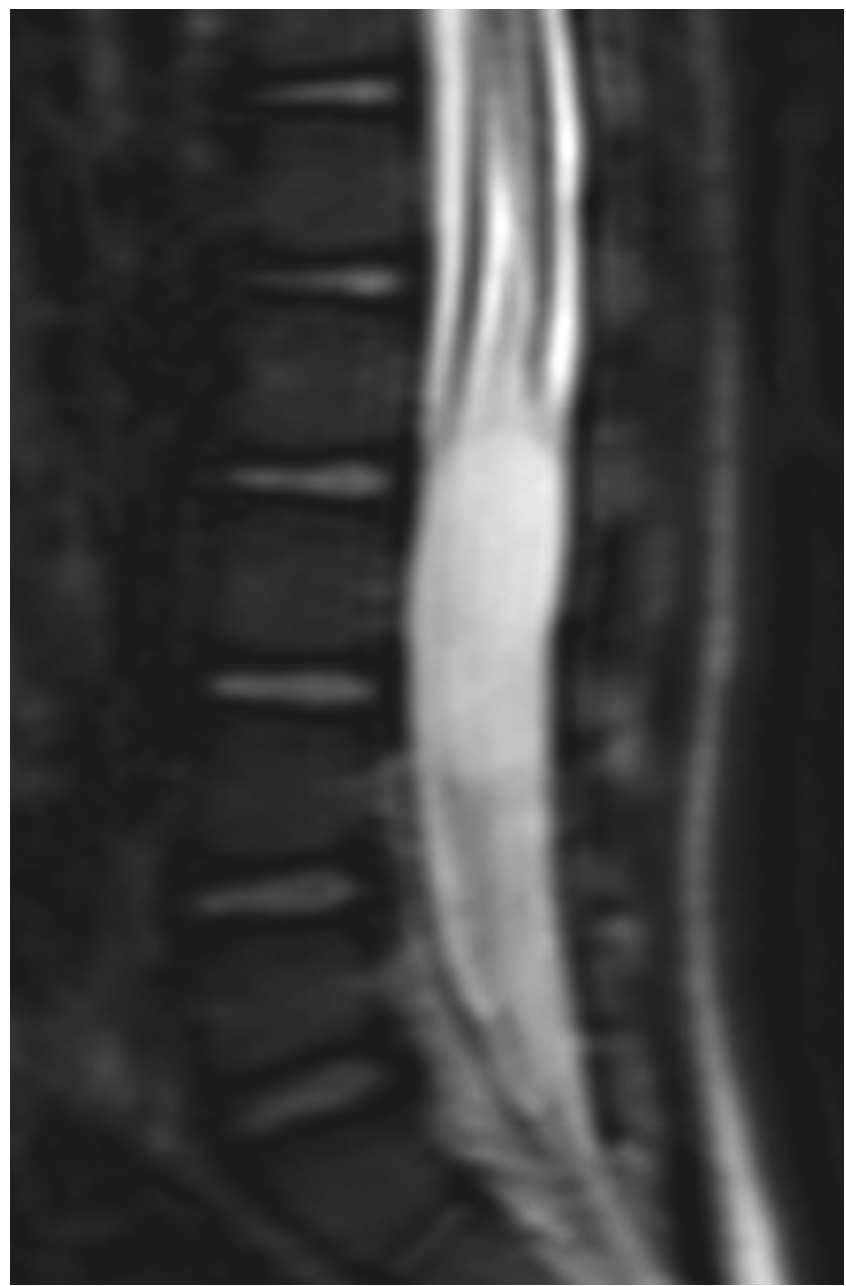

FIG. 3. Three-dimensional T2-weighted driven equilibrium (DRIVE) MR image, obtained at the fourth episode of gait disturbance, showing an enlarged mobile cyst.
Spinal enterogenous cysts are believed to originate from an anomalous embryological connection between the primitive foregut and the developing neural tube, probably in association with splitting or reduplication of the intervening notochord. ${ }^{11}$ This results in various malformations whose severity depends on the degree to which abnormal communication persists. Vertebral abnormalities, including spina bifida and vertebral body defects, are found in about $50 \%$ of patients with spinal enterogenous cysts. ${ }^{1}$ Most lesions are situated anteriorly within the spinal canal and thus may communicate with a mediastinal or abdominal cyst through a defect in the vertebral body. ${ }^{13}$ In our patient, no associated malformations such as vertebral anomaly or mediastinal or abdominal cyst were found. In a review of pediatric cases, the most common signs and symptoms of enterogenous cysts were compression of the spinal cord ( $75 \%$ of cases), paresis of a cranial nerve $(12.5 \%)$, meningitis or infectious syndrome $(12.5 \%)$, and intracranial hypertension (6\%). Overall, $37.5 \%$ of patients presented with bone malformations, $25 \%$ with cutaneous anomalies (dorsal meningocele, hairy patch, cutaneous hemangioma, and subcutaneous mass), and $18 \%$ with other malformations (clubfoot, rib and thorax anomalies, and abdominal anomalies). ${ }^{5}$ Our patient presented with symptoms caused by intermittent compression of the conus medullaris and cauda equina. The symptoms depended on the cyst location and size.

\section{Mechanism of Mobility and Size Fluctuation}

To our knowledge, this is the first reported case of a mobile spinal neurenteric cyst. In all previous case reports, the cysts were immobile and the symptoms were progressive. ${ }^{3}$ The natural history and factors responsible for cyst growth are unclear. Symptomatic expansion of enterogenous cysts may result from CSF accumulation in the cyst due to an osmotic effect after scarring and resealing of fenestrations in the cyst wall. ${ }^{6}$ Recurrent manifestations of cord compression might be caused by periodic cyst rupture, intraluminal absorption of intracystic fluid,
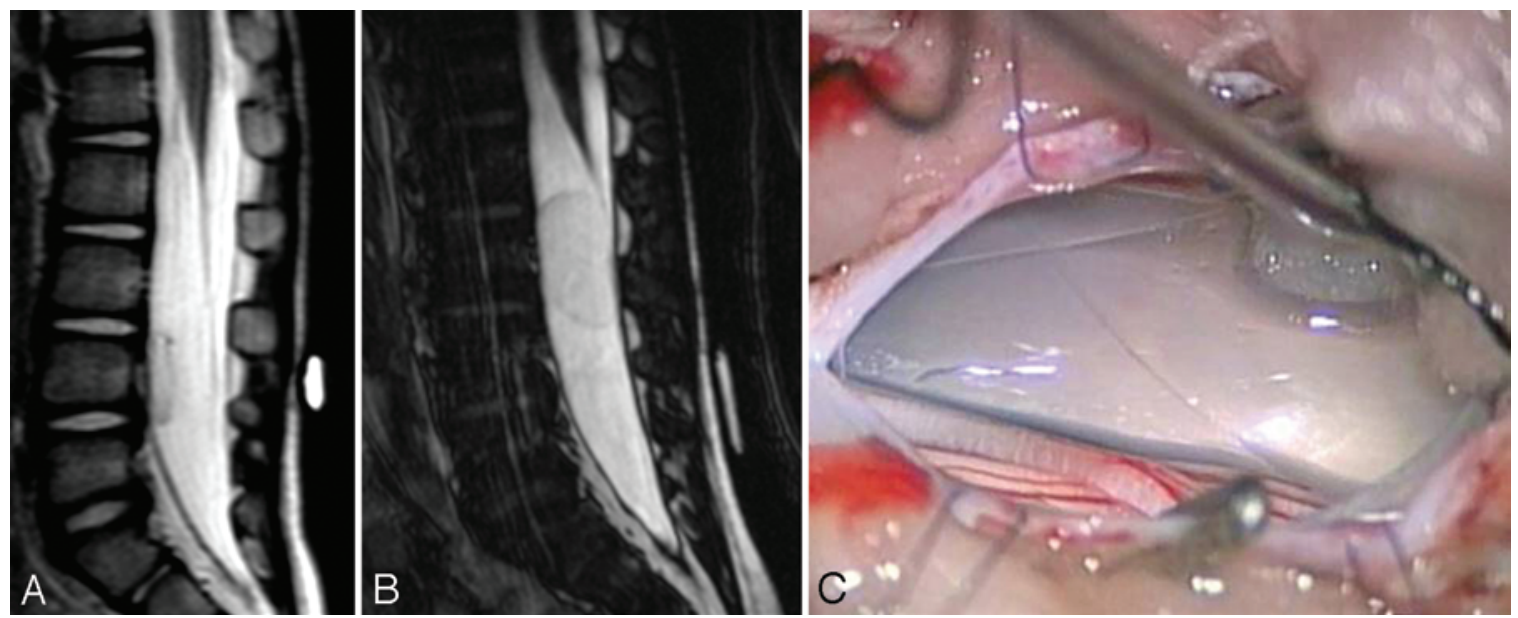

FIG. 4. A: Preoperative MR image showing the cyst had dramatically decreased in size. B: Three-dimensional fast imaging employing steady-state acquisition (FIESTA) sequence showing a newly enlarged cyst 2 days before surgery. C: Intraoperative photograph showing the thin-walled translucent cyst, which was located in the subarachnoid space, ventral to the cauda equina. Figure is available in color online only. 


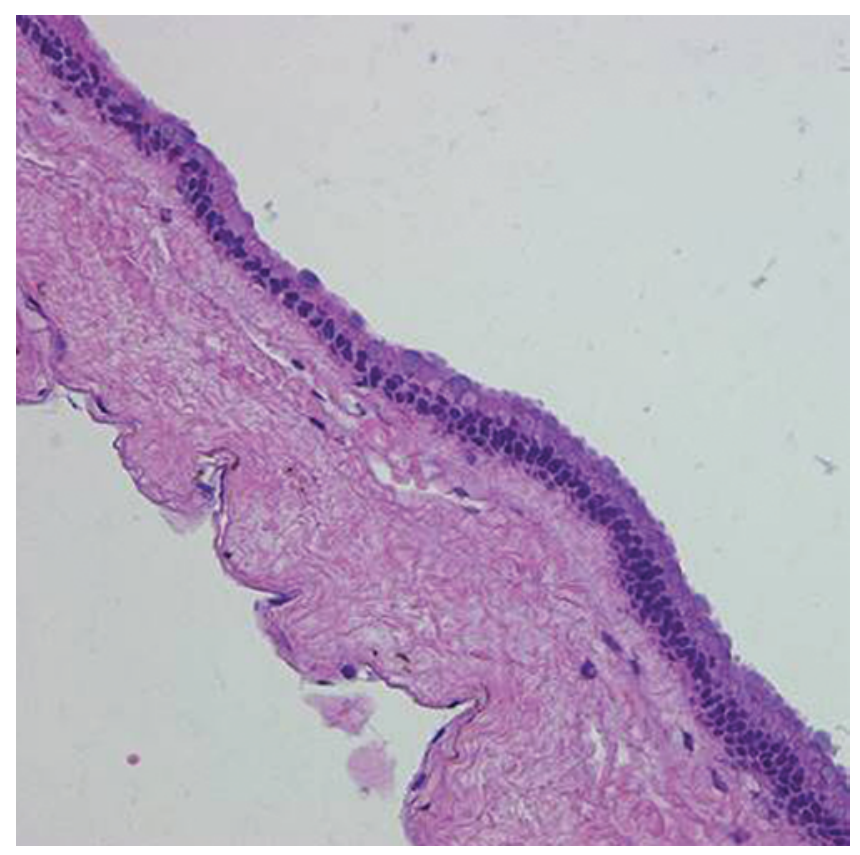

FIG. 5. Photomicrograph of the surgical specimen showing the cyst wall lined with columnar epithelium. $\mathrm{H} \& \mathrm{E}$, original magnification $\times 100$. Figure is available in color online only.

or changes in the osmotic pressure of cystic fluid. ${ }^{7}$ In our case, we speculated that the cyst demonstrated repeated ruptures and resealing. Moreover, the cyst did not adhere to surrounding structures, which caused it to shift position in the spinal canal as the patient changed posture.

\section{Differential Diagnosis}

The differential diagnosis for transient myelopathy or compression of the cauda equina includes multiple sclerosis, epidermoid cyst, spinal lipoma, congenital dermal sinus tract, cystic intradural extramedullary tumor including schwannoma, and arachnoid cyst. Computed tomography and MRI are essential for prompt diagnosis. In the present case, an isolated intradural extramedullary cyst with an undetectable vertebral defect caused intermittent neurological symptoms. Our preoperative diagnosis was arachnoid cyst. It is difficult to differentiate enterogenous cysts from arachnoid cysts. Arachnoid cysts are not always attached to the surrounding cord, although such attachment is sometimes observed in enterogenous cysts. ${ }^{7}$ Spinal enterogenous cysts are located ventrally, usually in an intradural and extramedullary position. They are isointense on T1-weighted images and hyperintense on T2-weighted unenhanced MR images. ${ }^{11}$ Spinal arachnoid cysts are usually intradural, posterior to the spinal cord, in a low- or midthoracic region. They have the same intensity as CSF on T1- and T2-weighted images and show no contrast enhancement. ${ }^{2}$ The clinical symptoms associated with enterogenous cysts and arachnoid cysts depend on the lesion site. Definitive diagnosis requires biopsy and histological examination. ${ }^{1}$ The walls of arachnoid cysts have a menin- geal structure and a complete absence of a columnar epithelial lining, which is a component of enterogenous cysts.

Although enterogenous cysts are rare, they are curable with total excision. Hence, enterogenous cyst should be considered in the differential diagnosis of spinal intradural cysts or spina bifida occulta in children with radiculomyelopathy.

\section{References}

1. Agnoli AL, Laun A, Schönmayr R: Enterogenous intraspinal cysts. J Neurosurg 61:834-840, 1984

2. Bakhti S, Djaadi L, Terkmani F, Tighilt N, Djennas M: Extradural spinal arachnoid cyst occurring in a child: a case report. Turk Neurosurg 24:90-93, 2014

3. de Oliveira RS, Cinalli G, Roujeau T, Sainte-Rose C, PierreKahn A, Zerah M: Neurenteric cysts in children: 16 consecutive cases and review of the literature. J Neurosurg 103 (6 Suppl):512-523, 2005

4. Ironside JW, Moss TH, Louis DN, Lowe JS, Weller RO: Diagnostic Pathology of Nervous System Tumours. London: Churchill Livingstone, 2002

5. Kaye AH, Laws ER Jr: Brain Tumors: An Encyclopedic Approach. London: Elsevier Health Sciences, 2011

6. Krishnamurthy G, Roopesh Kumar VR, Rajeswaran R, Rao S: Supratentorial enterogenous cyst: a report of two cases and review of literature. Neurol India 58:774-777, 2010

7. Lazareff JA, Hoil Parra JA: Intradural neurenteric cyst at the craniovertebral junction. Childs Nerv Syst 11:536-538, 1995

8. LeDoux MS, Faye-Petersen OM, Aronin PA, Vaid YN, Pitts RM: Lumbosacral neurenteric cyst in an infant. Case report. J Neurosurg 78:821-825, 1993

9. Mendel E, Lese GB, Gonzalez-Gomez I, Nelson MD, Raffel C: Isolated lumbosacral neurenteric cyst with partial sacral agenesis: case report. Neurosurgery 35:1159-1163, 1994

10. Menezes AH: Craniovertebral junction neoplasms in the pediatric population. Childs Nerv Syst 24:1173-1186, 2008

11. Menezes AH, Traynelis VC: Spinal neurenteric cysts in the magnetic resonance imaging era. Neurosurgery 58:97-105, 2006

12. Savage JJ, Casey JN, McNeill IT, Sherman JH: Neurenteric cysts of the spine. J Craniovertebr Junction Spine 1:58-63, 2010

13. Swischuk LE: Imaging of the Newborn, Infant, and Young Child. Philadelphia: Lippincott Williams \& Wilkins, 2004

\section{Disclosures}

The authors report no conflict of interest concerning the materials or methods used in this study or the findings specified in this paper.

\section{Author Contributions}

Conception and design: Kojima. Acquisition of data: Kojima. Analysis and interpretation of data: Kojima. Drafting the article: Kojima, Yoshimura. Critically revising the article: Yoshimura. Reviewed submitted version of manuscript: Yoshimura, Takao, Tamura, Nishiyama, Maruyama, Suda, Fujii. Study supervision: Yoshimura.

\section{Correspondence}

Satoko Kojima, Tokamachi Hospital, Takayama, Tokamachi City, Niigata 948-0055, Japan. email: m03034sk@jichi.ac.jp. 